\title{
Suicide risk assessment: examining transitions in suicidal behaviors among pregnant women in Perú
}

\section{( 国 Article in press ? )}

- Levey, E.J. ${ }^{\mathrm{a}, \mathrm{b}, \mathrm{c}}$ Email Author,

- $\quad$ Rondon, M.B. ${ }^{\mathrm{d}}$,

- Sanchez, S. ${ }^{\mathrm{e}}$,

- Zhong, Q.-Y.

- Williams, M.A. ${ }^{\mathrm{f}}$,

- ${\text { Gelaye, } \text { B. }^{\mathrm{f}}}^{-\mathrm{V}}$

- View Correspondence (jump link)

- $\quad{ }^{a}$ The Chester M. Pierce, MD Division of Global Psychiatry, Massachusetts General Hospital, 151 Merrimac St, 4th Floor, Boston, MA 02114, United States

- ${ }^{\mathrm{b}}$ Harvard Medical School, Boston, MA 02115, United States

- ' Institute for Juvenile Research, University of Illinois College of Medicine, Chicago, IL 60608, United States

$\underline{\text { View additional affiliations }}$

\begin{abstract}
The goals of this research were to characterize suicidal behavior among a cohort of pregnant Peruvian women and identify risk factors for transitions between behaviors. The World Health Organization Composite International Diagnostic Interview suicide questionnaire was employed to assess suicidal behavior. Discrete-time survival analysis was used to study the cumulative age-of-onset distribution. The hazard function was calculated to assess the risk of onset of each suicidal behavior. Among 2062

participants, suicidal behaviors were endorsed by $22.6 \%$ of participants; $22.4 \%$ reported a lifetime history of suicidal ideation, $7.2 \%$ reported a history of planning, and $6.0 \%$ reported attempting suicide. Childhood abuse was most strongly associated with suicidal behavior, accounting for a 2.57 -fold increased odds of suicidal ideation, nearly 3 -fold increased odds of suicide planning, and 2.43-fold increased odds of suicide attempt. This study identified the highest prevalence of suicidal behavior in a population of pregnant women outside the USA. Diverse populations of pregnant women and their patterns of suicidal behavior transition must be further studied. The association between trauma and suicidal behavior indicates the importance of trauma-informed care for pregnant women. (C) 2018 Springer-Verlag GmbH Austria, part of Springer Nature
\end{abstract}

\section{Author keywords}

PeruPregnantRisk assessmentSuicide

- ISSN: 14341816

- CODEN: AWMHF 
- Source Type: Journal

- Original language: English

- DOI: $10.1007 / \mathrm{s} 00737-018-0884-4$

- Document Type: Article in Press

- Publisher: Springer-Verlag Wien 